\title{
Variation of radon concentrations in soil and groundwater and its correlation with radon exhalation rate from soil in Budhakedar, Garhwal Himalaya
}

\author{
Ganesh Prasad, Yogesh Prasad, G S Gusain, Manjari Badoni, J M S Rana and R C Ramola* \\ Department of Physics, H N B Garhwal University, Badshahi Thaul Campus, \\ Tehri Garhwal-249 199, Uttarakhand, India \\ E-mail : rcramola@bsnl.in
}

\begin{abstract}
Radon was measured in soil-gas and groundwater in the Budhakedar area of Tehri Garhwal, India in summer and winter to obtain the seasonal variation and its correlation with radon exhalation rate. The environmental surface gamma dose rate was also measured in the same area. The radon exhalation rate in the soil sample collected from different geological unit of Budhakedar area was measured using plastic track detector (LR-115 type II) technique. The variation in the radon concentration in soil-gas was found to vary from 1098 to $31,776 \mathrm{~Bq} \cdot \mathrm{m}^{-3}$ with an average of $7456 \mathrm{~Bq} \cdot \mathrm{m}^{-3}$ in summer season and 3501 to $42883 \mathrm{~Bq} \cdot \mathrm{m}^{-3}$ with an average of $17148 \mathrm{~Bq} \cdot \mathrm{m}^{-3}$ in winter season. In groundwater, it was found to vary from 8 to $3047 \mathrm{~Bq} . \mathrm{I}^{-1}$ with an average value $510 \mathrm{~Bq} . \mathrm{I}^{-1}$ in summer and 26 to $2311 \mathrm{~Bq} . \mathrm{I}^{-1}$ with an average value $433 \mathrm{~Bq} . \mathrm{L}^{-1}$ in winter. Surface gamma dose rate in the study area varied from 32.4 to $83.6 \mu R \cdot h^{-1}$ with an overall mean of $58.7 \mu R . h^{-1}$ in summer and 34.6 to $79.3 \mu R \cdot h^{-1}$ with an average value $58.2 \mu R \cdot h^{-1}$ in winter. Radon exhalation rate from collected soil samples was found to vary from $0.1 \times 10^{-5}$ to $5.7 \times 10^{-5} \mathrm{~Bq} \cdot \mathrm{kg}^{-1} \cdot \mathrm{h}^{-1}$ with an average of $1.5 \times 10^{-5} \mathrm{~Bq} \cdot \mathrm{kg}^{-1} \cdot \mathrm{h}^{-1}$ in summer season and $1.7 \times 10^{-5}$ to $9.6 \times 10^{-5} \mathrm{~Bq} \cdot \mathrm{kg}^{-1} \cdot \mathrm{h}^{-1}$ with an average of $5.5 \times 10^{-5} \mathrm{~Bq} \cdot \mathrm{kg}^{-1} \cdot \mathrm{h}^{-1}$. A weak negative correlation was observed between radon exhalation rate from soil and radon concentration in the soil. Radon exhalation rate from the soil was also not found to be correlated with the gamma dose rate, while it shows a positive correlation with radon concentration in water in summer season. Inter-correlations among various parameters are discussed in detail.
\end{abstract}

Keywords : Radon, gamma dose rate, exhalation rate, soil, groundwater.

PACS Nos. : 92.60.Sz, 89.60.-k

\section{Introduction}

Radon is a product of the natural radioactive decay of uranium, which occurs naturally in the earth's crust, to radium and then to radon. As radium decays, radon is formed and is released into small air or water-containing pores between soil and rock particles. If this occurs near the soil surface, the radon may be released to ambient air. Radon may also be released into groundwater. If this groundwater reaches the surface, most of the radon gas will quickly be released to ambient air, but small amounts may 
remain in the water, by far, the major source of radon is its formation in and release from soil and groundwater, with soil contributing the greater amount. Smaller amount of radon are released from the near surface water of oceans, tailings from mines (particularly uranium and phosphate mines), coal residues and combustion products, natural gas, and building products, such as concrete and brick. The exposure to natural radiation sources varies substantially from space to place and even locally [1]. The main natural contributors to external exposure from $\gamma$-radiation are the members of the uranium and thorium series together with $40 \mathrm{~K}$, the radionuclides that are universally present in small quantities in the crust of Earth

Radon $\left({ }^{222} \mathrm{Rn}\right)$ a naturally occurring $\alpha$-emitting radioactive noble gas, is ubiquitous at the Earth's surface. It is the daughter of ${ }^{226} \mathrm{Ra}$ in the ${ }^{238} \mathrm{U}$ series. It is estimated that the average concentration of uranium in soil is $35 \mathrm{~Bq} \cdot \mathrm{kg}^{-1}[2,3] .{ }^{222} \mathrm{Rn}$ with a halflife of $3.8 \mathrm{~d}$ is the most important among the radon isotopes. ${ }^{220} \mathrm{Rn}$ and ${ }^{219} \mathrm{Rn}$, owing to their short half-lives, have lower levels. Although radium occurs in virtually all types of rock and soil, its concentration varies with the specific site and geological material [4-6]. The major source of human exposure consists of radon and its daughters in buildings, due to radon emanation from building materials and from the ground below. In some countries, the radiation dose to man caused by inhaled radon daughters constitutes more then $50 \%$ of the total dose $[3,7]$. The groundwater radon concentration is expected to reflect not radon concentration is expected to reflect not only in chemical form but also in structural properties of rock in an aquifer [8]. The radon concentration in groundwater is basically proportional to uranium concentration in adjacent rocks and soil in an aquifer, hydrothermal solution and with variations in stress in rocks associated with seismicity and also is usually higher than surface water. The radon content of soil gas is not directly a function of the radium and uranium concentration of the soil. The factors that affect the radon concentration in soil-gas are the radium distribution, porosity, the moisture content and density of soil, the underlying bedrock and the meteorological parameters $[9,10]$. The measurement of terrestrial gamma radiation dose rate with the measurements of radon and thoron is therefore desirable and possibly necessary in order to find the total radiation dose to the people living in the area. Emanation of radon atoms from mineral grain are controlled by the situation of radium atoms in the grain, texture, size of grain, temperature and pressure [11-13].

\section{Experimental methods}

The measurements of radon in soil and water, gamma dose rate and radon exhalation rate have been carried out by using radon emanometer, environmental radiation dosimeter and track-etch method, respectively. Brief descriptions of these techniques are as follows :

\subsection{Radon emanometry :}

For the measurements of radon in spring water, a radon tight reagent bottle of one liter 
capacity holds $750 \mathrm{ml}$ water was taken. The reagent bottle was connected in a closed circuit with a $\mathrm{ZnS}$ coated detection chamber through an electric bubbler and a glass tube containing $\mathrm{CaCl}_{2}$ to absorb any moisture. The air was circulated in a closed circuit for a period of 15 min until the radon forms a uniform mixture with the air and resulting counts were recorded. The detector was then isolated by clamping at both the ends and observations were taken after a period of four hours. A time-gap of four hours is necessary to allow the alpha-emitting daughters of radon, $\mathrm{RaA}$, and $\mathrm{RaC}$, to come in equilibrium with their own daughters. The alpha-particles produce scintillations on the sample chamber, which are sensed by photomultiplier and converted to an electronic meter reading. The calibration factor of $1 \mathrm{count} / \mathrm{min}=0.0663 \mathrm{~Bq} / \mathrm{l}$ was used to convert the recorded alpha counts to $\mathrm{Bq} / \mathrm{l}[14]$.

For the measurement of radon in soil-gas, the auger holes, each $60 \mathrm{~cm}$ in depth and $6 \mathrm{~cm}$ in diameter are left covered for 24 hours so that the amount of radon and thoron became stable. A soil-gas probe is fixed in the auger hole and forms an air tight compartment [15]. The electric pump/hand operated pump, soil-gas probe and alpha-detector were connected in closed circuit. The air is circulated through a ZnS coated chamber for a period of 15 minutes till the radon forms a uniform mixture with the air. The resulting counts were recorded and converted into Bq. $\mathrm{m}^{-3}$ by using the appropriate calibration factor [14].

\subsection{Measurement of radon exhalation rate :}

When the holes were drilled for radon measurements, about $500 \mathrm{gm}$ soil sample was taken exactly from the same location for laboratory analysis. In this laboratory experiment, the track-etch method was used to measure the exhalation rate of radon from the soil sample collected from the field. In this technique, LR-115 Type II, plastic track detectors were fixed on the top inside of a cylindrical can, $30 \mathrm{~cm}$ height and 12 $\mathrm{cm}$ diameter. The cans were sealed for one month. The detectors were then removed, etched and scanned for track density measurements. The resulting density was then converted in Bq. $\mathrm{m}^{-3}$ by appropriate calibration factor [16] and the exhalation rate is obtained by the relation [17].

$$
E_{x}=C V \lambda / M\left[T+1 / A\left(e^{-\lambda t}-1\right)\right]
$$

where $E_{x}$ is the radon exhalation rate $\left(\mathrm{Bq} \cdot \mathrm{kg}^{-1} \cdot \mathrm{h}^{-1}\right), C$ is the measured radon concentration (Bq. $\left.\mathrm{m}^{-3} \cdot \mathrm{h}^{-1}\right), V$ is the effective volume of the can $\left(\mathrm{m}^{3}\right), \lambda$ is the decay constant for radon $\left(\mathrm{h}^{-1}\right), T$ is the exposure time $(h)$, and $M$ is mass of the sample.

\subsection{Measurement of surface gamma dose rate :}

The surface gamma dose rate was measured by using a portable gamma spectrometer (Type ERQ705, Nucleonix system, Hyderabad, India). It is designed using a highly sensitive G.M. Detector and operates on Ni-Cd battery, which can run continuously for 200 hours. It is designed to read exposure rate in two ranges with measuring 
sensitivity of $0.1 \mu R / h$ and $1 \mu R / h$, and cumulative exposure with a measuring sensitivity of $1 \mu \mathrm{R} / \mathrm{h}$, respectively. This battery operated instrument is switched on at the measurement spot for about half an hour, which instantaneously records the gamma radiation dose rate in $\mu \mathrm{R} / \mathrm{h}$. The indoor measurements were made by putting the dosimeter on the ground and then at a height of 1 metre from the ground. The mean value was calculated and recorded for each pair of measurements.

\section{Results and discussion}

The measured values of radon concentrations in soil-gas, groundwater and the exhalation rate of radon from collected samples for summer and winter are shown in Table 1.

Table 1. Concentrations of radon in soil-gas, groundwater along with surface gamma dose rate and radon exhalation rate.

\begin{tabular}{|c|c|c|c|c|c|c|c|c|}
\hline \multirow[t]{2}{*}{ Location } & \multicolumn{2}{|c|}{$\begin{array}{l}\text { Soil-gas radon } \\
\text { concentration } \\
\qquad\left(\mathrm{Bq} / \mathrm{m}^{3}\right)\end{array}$} & \multicolumn{2}{|c|}{$\begin{array}{l}\text { Radon concentration } \\
\text { in water }(\mathrm{Bq} / \mathrm{l})\end{array}$} & \multicolumn{2}{|c|}{$\begin{array}{c}\text { Gamma dose rate } \\
(\mu \mathrm{R} / \mathrm{h}) \text { rate }\end{array}$} & \multicolumn{2}{|c|}{$\begin{array}{l}\text { Radon exhalation } \\
\begin{array}{c}\left(\mathrm{Bq} \cdot \mathrm{kg}^{-1} \cdot \mathrm{h}^{-1}\right) \\
\times 10^{-5}\end{array}\end{array}$} \\
\hline & Summer & Winter & Summer & Winter & Summer & Winter & Summer & Winter \\
\hline Budhakedar (H) & $1591 \pm 563$ & $3501 \pm 527$ & $3047 \pm 25$ & $2311 \pm 21$ & $44.7 \pm 0.5$ & $42.3 \pm 0.3$ & $5.71 \pm 0.27$ & $5.9 \pm 0.52$ \\
\hline Kamala Nagar & $8195 \pm 807$ & $12809 \pm 1009$ & $50 \pm 2$ & $28 \pm 1$ & $67.6 \pm 0.2$ & $66.6 \pm 0.5$ & $1.31 \pm 0.06$ & $4.9 \pm 0.13$ \\
\hline Aagar & $1114 \pm 298$ & $19253 \pm 1237$ & $1585 \pm 18$ & $519 \pm 6$ & $83.6 \pm 0.3$ & $48.4 \pm 0.2$ & $0.63 \pm 0.06$ & $7.9 \pm 0.19$ \\
\hline Aagreswat Temple & $6715 \pm 733$ & $8911 \pm 842$ & $290 \pm 7$ & $1378 \pm 10$ & $51.1 \pm 0.9$ & $57.3 \pm 0.3$ & $0.82 \pm 0.09$ & $9.6 \pm 0.24$ \\
\hline Aagar end & $6715 \pm 733$ & $20289 \pm 1270$ & $768 \pm 8$ & $208 \pm 4$ & $55.2 \pm 0.7$ & $56 \pm 0.7$ & N.A & $6.3 \pm 0.17$ \\
\hline Niwal Gaon & N.A & N.A & $8 \pm 1$ & N.A & $32.4 \pm 0.2$ & $39.6 \pm 0.5$ & $0.15 \pm 0.03$ & $5.2 \pm 0.15$ \\
\hline Niwal Gaon II & N.A & N.A & $38 \pm 2$ & $107 \pm 3$ & $33.7 \pm 0.6$ & $34.6 \pm 0.4$ & $0.32 \pm 0.04$ & $1.7 \pm 0.79$ \\
\hline Ghurdi & N.A & $14400 \pm 1070$ & $149 \pm 3$ & $178 \pm 4$ & $58.8 \pm 0.2$ & $60 \pm 0.7$ & $0.07 \pm 0.02$ & $3.6 \pm 0.11$ \\
\hline Agunda Road & $31776 \pm 1591$ & $10820 \pm 927$ & $167 \pm 4$ & $26 \pm 1$ & $76.8 \pm 0.8$ & $79.3 \pm 0.9$ & $0.28 \pm 0.05$ & $8.7 \pm 0.19$ \\
\hline Agunda start & N.A & $10343 \pm 907$ & $92 \pm 3$ & $84 \pm 2$ & $59.9 \pm 0.5$ & $63.3 \pm 0.4$ & $0.25 \pm 0.05$ & $9.1 \pm 0.23$ \\
\hline Agunda village & $1098 \pm 293$ & $27050 \pm 1466$ & $221 \pm 4$ & $412 \pm 6$ & $66.7 \pm 0.9$ & $64.3 \pm 0.5$ & $0.61 \pm 0.06$ & $5.9 \pm 0.14$ \\
\hline Bishan School & $2785 \pm 471$ & $31665 \pm 1587$ & $186 \pm 4$ & $59 \pm 2$ & $65.4 \pm 0.4$ & $70 \pm 0.6$ & $2.93 \pm 0.13$ & $2.2 \pm 0.74$ \\
\hline Budhakedar (source) & $7113 \pm 754$ & $3262 \pm 509$ & $426 \pm 6$ & $1075 \pm 9$ & $55.6 \pm 0.3$ & $58.3 \pm 0.3$ & $3.67 \pm 0.15$ & $3.1 \pm 0.85$ \\
\hline Saunala (Vinaykhal) & N.A & N.A & $123 \pm 5$ & $56 \pm 2$ & $67.2 \pm 0.4$ & $70 \pm 0.4$ & $3.31 \pm 0.18$ & $7.4 \pm 0.20$ \\
\hline Agunda land slide & N.A & N.A & N.A & N.A & N.A & N.A & $0.40 \pm 0.05$ & $2.3 \pm 0.86$ \\
\hline Bishan road & N.A & $42883 \pm 1847$ & N.A & $110 \pm 3$ & N.A & $50 \pm 0.3$ & $1.86 \pm 0.10$ & $5.7 \pm 0.14$ \\
\hline Rashagram Shabha & N.A & $21242 \pm 1299$ & N.A & $289 \pm 5$ & N.A & $71.3 \pm 0.8$ & N.A & $3.7 \pm 0.10$ \\
\hline Ghurdi II & N.A & N.A & N.A & $101 \pm 3$ & N.A & N.A & N.A & N.A \\
\hline
\end{tabular}

The radon concentration in soil-gas was found to vary from $1098 \pm 293$ to $31776 \pm$ $1591 \mathrm{~Bq} \cdot \mathrm{m}^{-3}$, with an average of $7456 \mathrm{~Bq} \cdot \mathrm{m}^{-3}$, while in groundwater it was found to vary from $8 \pm 1$ to $3047 \pm 25$ Bq. $\mathrm{I}^{-1}$, with an average of $510 \mathrm{~Bq} . \mathrm{I}^{-1}$. The radon exhalation rate from the collected soil samples range between $0.1 \pm 0.02\left(\times 10^{-5}\right)$ and $5.7 \pm 0.27\left(\times 10^{-5}\right)$ Bq. $\mathrm{kg}^{-1} \cdot \mathrm{h}^{-1}$ in summer. In winter, the radon concentration in soil-gas 
gas was found to vary from $3501 \pm 527$ to $42883 \pm 1847$ Bq. ${ }^{-3}$, with an average of 17184 Bq. $\mathrm{m}^{-3}$, while in groundwater it was found to vary from $26 \pm 1$ to $2311 \pm$ $21 \mathrm{~Bq} . \mathrm{l}^{-1}$ with an average of $433 \mathrm{~Bq} \cdot \mathrm{l}^{-1}$. The radon exhalation rate from the collected soil samples range between $1.7 \pm 0.79\left(\times 10^{-5}\right)$ to $9.6 \pm 0.24\left(\times 10^{-5}\right) \mathrm{Bq} \cdot \mathrm{kg}^{-1} \cdot \mathrm{h}^{-1}$.

The average surface gamma dose rate in the study area was found to be 58.7 with the highest value, $83.6 \pm 0.3 \mu R \cdot \mathrm{h}^{-1}$, measured at Agar village near Budhakedar and lowest value, $32.4 \pm 0.2 \mu R \cdot h^{-1}$ measured at Niwal Gaon in summer season and the average surface gamma dose rate in the study area was found to be $58.2 \mu R \cdot \mathrm{h}^{-1}$ with the highest value, $79.3 \mu R \cdot h^{-1}$, measured at Agunda Road and the lowest value $34.6 \mu R \cdot h^{-1}$ measured at Niwal Gaon II in winter season. Radon concentrations in soilgas and groundwater were also observed to be higher at this place. The highest value of soil-gas radon was measured at Agunda Road (summer season) about $200 \mathrm{~m}$ from Budhakedar in and the highest value of soil-gas radon was measured at Bishan Road (winter season) about $500 \mathrm{~m}$ from Budhakedar.

Radon exhalation rate from the soil samples of the study areas were also not found to correlate with the surface gamma dose rate, which is again because of the reason discussed above. However, a weak negative correlation was observed between soil-gas radon concentration and radon exhalation rate from the collected soil. This again verifies the fact that the observed radon concentration in soil-gas is mainly due to presence of mineralization in the area. The soil of the earth's surface does not contribute much to soil-gas radon concentration and surface gamma dose rate may be due to the presence of other radionuclides at the earth's surface. However, a positive correlation was observed between radon exhalation rate from soil and radon concentration in groundwater.

\section{Conclusions}

It was found that radon concentrations in soil-gas and groundwater and surface gamma dose rate are governed by the lithology of the study area. A weak negative correlation was observed between radon exhalation rate from soil and radon concentration in the soil. Radon exhalation rate from the soil was also not found to be correlated with the gamma dose rate, while it shows a positive correlation with radon concentration in water in summer season and a weak negative correlation was observed between radon exhalation rate from soil-gas and positive correlation with radon concentration in ground water in winter season. The high values of soil-gas radon concentrations are mainly because of migration of radon through a thrust are and the presence of uranium mineralization in the area.

\section{Acknowledgments}

Authors are thankful to Council of Scientific and Industrial Research, New Delhi and Board of Research in Nuclear Sciences, Department of Atomic Energy, Government of 
India for providing financial support in the form of project.

\section{References}

[1] UNSCEAR, lonizing Radiation Sources and Biological Effects (New York : United Nations) (1982)

[2] M C Robe and V Labed Explaining the variation in soil radon concentrations : a study of the influence of some intrinsic properties of a rock matrix on the radon emission factor. in : C Dubois (ed.) Gas Geochemistry, Environ. Geochem. Health, Science Reviews, Northwood, 16535 (1995)

[3] UNSCEAR, Sources and Effects of lonizing Radiation (New York : United Nations) (2000)

[4] L C S Gundersen, J K O Schumann, R F Dubiel and D E Owen Geology of radon in United States. in : A E Gates, L C EGunersen (eds.) Geological Control of Radon. Geol. Soc. Am. Spl. Paper 2711 (1992)

[5] V M Choubey and R C Ramola J. Environ. Geol. 32258 (1997)

[6] V M Choubey, K S Bist, N K Saini and R C Ramola J. Appl. Radiat. Iso. 51587 (1999)

[7] J H Lubin and (Jr.) J D Boice J. Nat. Can. Inst. 8949 (1993)

[8] G Igarashi, S Saeki, N Takahata, K Sumikawa, S Tasaka, Y Sasaki, M Takahashi and Y Sano Science 269 60 (1995)

[9] C King J. Geophys. Res. 91-B 1212269 (1986)

[10] S Abbad, M C Robe, M Bernat and V Labed Influence of meteorological and geological parameter variables on the concentration of radon in soil gases: application on seismic forecasting in the ProvinceAlpes-Cote d'Azur region. in : C Dubois (ed.), Gas Geochemistry, Environ. Geochem. Health, Sci. Reviews, Northwood 1635 (1995)

[11] R L Fleischer Science 207979 (1980)

[12] A B Tanner Radon migration in the ground : a supplementary review, in Natural Radiation Environment III, (eds.) T F Gesell and W M Lowder CONF-780422 15 (1980)

[13] P Anderson, B Clavensjo, G Akerblom The effect of the ground on the concentration of radon and gamma radiation indoors. Swedish Council for Building Research Report R9 1 (1983)

[14] V M Choubey, T V Ramachandran, M S Negi and R C Ramola Indian J. Environ. Prot. 20329 (2000)

[15] R C Ramola, A S Sandhu, M Singh, S Singh and H S Virk Nucl. Geophy. 357 (1989)

[16] R C Ramola, R B S Rawat, M S Kandari, T V Ramachandran, K P Eappen and M C Subba Ramu Indoor Built Environ. 5364 (1996)

[17] R C Ramola and V M Choubey J. Radioanal. Nucl. Chem. 256219 (2003) 